Corresponding author Phone: +421556023545

E-mail address:jan.slota@tukesk

(Ján Slota, doc. Ing. PhD.)

Article information

Article history: AMS-Volume15-No.4-00133-11

Received 12 April 2011

Accepted 12 May 2011

\section{Raman Spectroscopy in Polymer Processing Technologies}

\author{
Ivan Gajdoš, František Greškovič, Ján Slota* , Ludmila Dulebová
}

Department of Technologies and Materials, Faculty of Mechanical Engineering, Mäsiarska 74, 04201 Košice, Slovak Republic

\section{BIOGRAPHICAL NOTES}

Ivan Gajdoš, Ing. PhD. Was born in 1980 in Stropkov, Slovakia and is assistant professor at Department of technologies and materials. He graduated in 2003 at Faculty of mechanical engineering, Technical University of Košice. He received his PhD. degree in field of polymer processing technologies in 2007 at Technical University in Košice. His research interest include polymer processing technologies,CAE simulations and additive manufacturing technologies. Mr. Gajdoš is co-author of one monography and book and has more than 30 publications in journals and conference proceedings home and abroad. He has worked on several grant projects and resaearc $h$ tasks.

František Greškovič, prof. Ing. CSc. (born 1956) is associated professor of Department of Technologies and Materials, Faculty of Mechanical Engineering, Technical University of Košice and Vice-Dean Faculty of Mechanical Engineering. He is graduate SjF TUKE in 1980, scientific degree Candidate 1996, profesor 2011. Professional orientation or specialisation: Technologies and Materials, Sheet Metal und Polymers Forming. The most relevant publication outputs : 170 publications, 127 publications in home and foreign journals.

Ján Slota, doc. Ing. PhD. (born 1974) is associated professor of Department of Technologies and Materials, Faculty of Mechanical Engineering, Technical University of Košice. He is graduated on Faculty of Mechanical Engineering, TU in Košice, where he received also scientific degree PhD and where he habilitated at the field of mechanical engineering processes and materials. From 2004, he has been head of section of Computer Aided of Production Engineering on the Department. His research works are mainly focused on the area of computer simulations in deep-drawing processes. He is a member of International Deep-Drawing Research Group. He is author of three university textbooks and more than 70 publications in journals and conference proceedings at Slovakia and abroad. He has been worked on several grant projects, research tasks and many projects solved for industry.

Ludmila Dulebová, Ing. PhD. is an assistant professor at the Department of Technologies and Materials, Faculty of Mechanical Engineering, Technical University of Kosice. Her research interests include processing technologies of plastics, testing of properties of plastics, influence of recyclate on their properties, monitoring of risks in the development of recycled products. She is co-author of one monography, one textbook and author of more than 90 papers published in home and international journals and proceedings from conferences.

\section{KEY WORDS}

Raman Spectroscopy, Polymer, Scattering

\section{ABSTRACT}

Presented paper describes the application of Raman spectrometry in polymer process- 
ing technologies. Quick and reliable material identification is becoming and serrious issue in polymer processign technologies. Vibrational spectroscopy was long time used in polymer analysis. Preferred technique was the infrared spectroscopy (IR), but actual progress allows easy application of Raman spectroscopy and its main advantages. Raman spectroscopy detects vibrations that generate a change in the molecule's polarizability. The Raman effect arises when a photon is incident on a molecule and interacts with the electric dipole of the molecule. It is a form of electronic (more accurately, vibronic) spectroscopy, although the spectrum contains vibrational frequencies. Modern palmsized Raman spectrometers allows simplified infield application. Quick online material identification on site is possible, or more specifical material characteristic is possible offline, when evaluating measured data with specialized software.

\section{Introduction}

Vibrational spectroscopy was long time used in polymer analysis. Preferred technique was the infrared spectroscopy (IR), but actual progress allows easy application of Raman spectroscopy and its main advantages. IR and Raman spectroscopy differ fundamentally in their mechanisms for detecting vibrations. IR spec- troscopy detects vibrations that generate a change in the molecule's dipole moment. Raman spectroscopy detects vibrations that generate a change in the molecule's polarizability. Some vibrations can be accompanied by changes in both dipole moment and polarizability; these vibrations are detected by both IR and Raman spectroscopy. In long polymer chains, vibrations of the backbone generally do not induce changes in the dipole moment because adjacent di- poles are cancelled out by repeating units, but the change in polarizability is usually high. This makes Raman spectroscopy particularly useful because it is highly sensitive to the structure and conformation of the polymer backbone. In contrast, IR can be useful for analyzing side chains, so the two techniques can be used complementarily [3].

In the past, Raman spectroscopy was hindered by fluorescence from samples that were highly colored or had fluorescent impurities. Today, however, excitation in the deep red and near-infrared (NIR) regions can be used, which avoids fluorescence in many samples. In addition, manufactur- ing practices for polymers have vastly improved, so potentially obstructive fluorescent impurities in otherwise non-fluorescent materials are not nearly as prevalent as in the past. Raman spectroscopy is easily incorporated as on-line or in-line process monitoring technique. Figure 1 shows a Raman probe being used to monitor a moving polymer film. Note that the probe does not come in contact with the film.

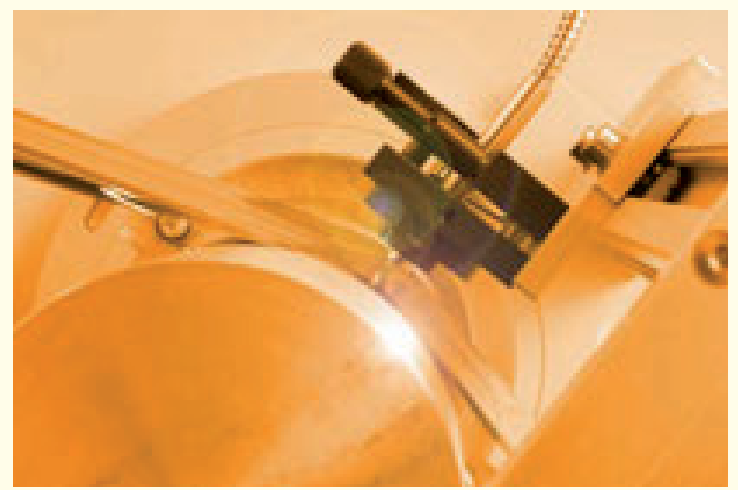

Fig. 1: Monitoring a moving polymer film line.

Raman spectroscopy can be used in several ways to get information from polymers. The simplest is to use the Raman spectrum as a "fingerprint" to quali- tatively identify polymeric materials. Infrared spectroscopy is an analytical technique designed for identification of organic compounds and inorganic substances [6].

\section{Raman scattering theory}

When light is scattered from a molecule most photons are elastically scattered. The scattered photons have the same energy (frequency) and, therefore, wavelength, as the incident photons. However, a small fraction of light (approximately 1 in 107 photons) is scattered at optical frequencies different from, and usually lower than, the frequency of the incident photons. The process leading to this inelastic scatter is the termed the Raman effect. Raman scattering can occur with a change in vibrational, rotational or electronic energy of a molecule. Chemists are concerned primarily with the vibrational Raman effect. We will use the term Raman effect to mean vibrational Raman effect only. The difference in energy between the incident photon and the Raman scattered photon is equal to the energy of a vibration of the scattering molecule. A plot of intensity of scattered light ver- 
sus energy difference is a Raman spectrum.

\section{Scattering Process}

The Raman effect arises when a photon is incident on a molecule and interacts with the electric dipole of the molecule. It is a form of electronic (more accurately, vibronic) spectroscopy, although the spectrum contains vibrational frequencies. In classical terms, the interaction can be viewed as a perturbation of the molecule's electric field. In quantum mechanics the scattering is described as an excitation to a virtual state lower in energy than a real electronic transition with nearly coincident de-excitation and a change in vibrational energy. The scattering event occurs in 10-14 seconds or less.

The energy lost by the photons in the scattering event is called the Raman shift and is defined in energy as $\Delta E_{R}=E_{L}-E_{S}$. It is therefore positive for a Stokes and negative for an anti-Stokes process. Raman shifts are commonly expressed in wavenumbers and will then be denoted $\Delta \nu_{R}$ (usually in units of $\left.\left[\mathrm{cm}^{-1}\right]\right)$. The modulus of the Raman shift corresponds to the wave-number of the vibrational mode $\left(\nu_{\mathrm{v}}=\mathrm{h}_{\omega \mathrm{\omega v}} / \mathrm{h}_{\mathrm{c}}\right)$ that was involved in the scattering event: $\nu_{\mathrm{v}}=\left|\Delta \nu_{\mathrm{R}}\right|$.

The Raman spectrum corresponds to the wavelength- (or energy-) dependence of the Raman scattered intensity at a given incident wavelength. It is commonly shown as Raman intensity as a function of Raman shift (rather than wavelength), as shown in Fig. 2. for an example SERS spectrum. Peaks in the Raman spectrum correspond to vibrational modes of the molecule, in a similar fashion as for an infrared absorption spectrum. The Raman shift of a peak is equal to the vibrational energy of the corresponding mode. There is some broadening (homogeneous and inhomogeneous) of the peaks, but Raman peaks for molecular compounds are typically'narrow' $\left(5-20 \mathrm{~cm}^{-1}\right)$.

At room temperature the thermal population of vibrational excited states is low, although not zero. Therefore, the initial state is the ground state, and the scattered photon will have lower energy (longer wavelength) than the exciting photon. This Stokes shifted scatter is what is usually observed in Raman spectroscopy. A small fraction of the molecules are in vibrationally excited states. Raman scattering from vibrationally excited molecules leaves the molecule in the ground state.

The scattered photon appears at higher energy.
This anti-Stokes-shifted Raman spectrum is always weaker than the Stokes-shifted spectrum, but at room temperature it is strong enough to be useful for vibrational frequencies less than about 1500 $\mathrm{cm}^{-1}$. The Stokes and anti-Stokes spectra contain the same frequency information. The ratio of antiStokes to Stokes intensity at any vibrational frequency is a measure of temperature. Anti-Stokes Raman scattering is used for contactless thermometry. The anti-Stokes spectrum is also used when the Stokes spectrum is not directly observable, for example because of poor detector response or spectrograph efficiency.

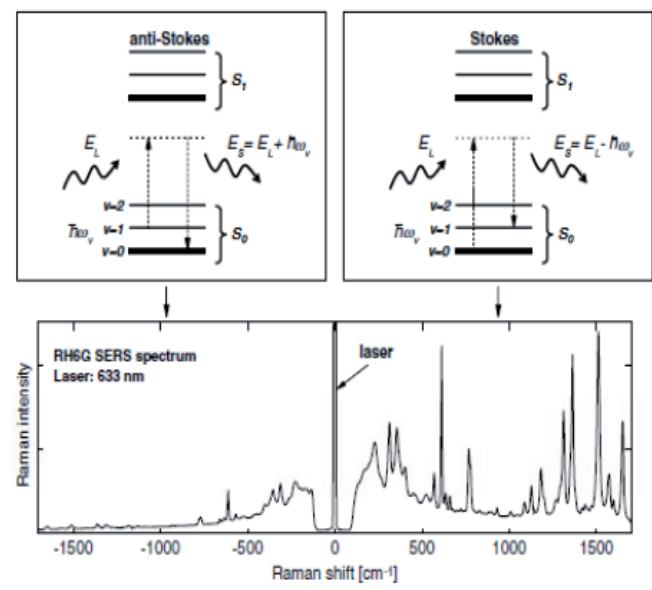

Fig. 2: Simplified Jablonski diagrams of the anti-Stokes (top left) and Stokes (top right).

At room temperature the thermal population of vibrational excited states is low, although not zero. Therefore, the initial state is the ground state, and the scattered photon will have lower energy (longer wavelength) than the exciting photon. This Stokes shifted scatter is what is usually observed in Raman spectroscopy. A small fraction of the molecules are in vibrationally excited states. Raman scattering from vibrationally excited molecules leaves the molecule in the ground state. The scattered photon appears at higher energy. This anti-Stokesshifted Raman spectrum is always weaker than the Stokes-shifted spectrum, but at room temperature it is strong enough to be useful for vibrational frequencies less than about $1500 \mathrm{~cm}^{-1}$. The Stokes and anti-Stokes spectra contain the same frequency information. The ratio of anti-Stokes to Stokes intensity at any vibrational frequency is a measure of temperature. Anti-Stokes Raman scattering is used 
for contactless thermometry. The anti-Stokes spectrum is also used when the Stokes spectrum is not directly observable, for example because of poor detector response or spectrograph efficiency.

\section{Vibrational Energies}

The energy of a vibrational mode depends on molecular structure and environment. Atomic mass, bond order, molecular substituents, molecular geometry and hydrogen bonding all effect the vibrational force constant which, in turn dictates the vibrational energy. For example, the stretching frequency of a phosphorus-phosphorus bond ranges from 460 to 610 to $775 \mathrm{~cm}^{-1}$ for the single, double and triple bonded moieties, respectively.[1] Much effort has been devoted to estimation or measurement of force constants. For small molecules, and even for some extended structures such as peptides, reasonably accurate calculations of vibrational frequencies are possible with commercially available software.

Vibrational Raman spectroscopy is not limited to intramolecular vibrations. Crystal lattice vibrations and other motions of extended solids are Ramanactive. Their spectra are important in such fields as polymers and semiconductors. In the gas phase, rotational structure is resolvable on vibrational transitions. The resulting vibration/rotation spectra are widely used to study combustion and gas phase reactions generally. Vibrational Raman spectroscopy in this broad sense is an extraordinarily versatile probe into a wide range of phenomena ranging across disciplines from physical biochemistry to materials science.

\section{Resonance-Enhanced Raman Scattering}

Raman spectroscopy is conventionally performed with green, red or near-infrared lasers. The wavelengths are below the first electronic transitions of most molecules, as assumed by scattering theory. The situation changes if the wavelength of the exciting laser within the electronic spectrum of a molecule. In that case the intensity of some Raman-active vibrations increases by a factor of 102 104. This resonance enhancement or resonance Raman effect can be quite useful.

The vibrations whose Raman bands are resonance enhanced fall into two or three general classes. The most common case is Franck-Condon enhancement, in which a component of the normal coordinate of the vibration is in a direction in which the molecule expands during an electronic excitation. The more the molecule expands along this axis when it absorbs light, the larger the enhancement factor. The easily visualized ring breathing (in-plane expansion) modes of porphyrins fall into this class. Vibrations which couple two electronic excited states are also resonance enhanced. This mechanism is called vibronic enhancement. In both cases enhancement factors roughly follow the intensities of the absorption spectrum. [2]

Resonance enhancement does not begin at a sharply defined wavelength. In fact, enhancement of $5 X-10 X$ is commonly observed if the exciting laser is even within a few hundred wave numbers below the electronic transition of a molecule. This pre-resonance enhancement can be experimentally useful.

\section{Raman spectroscopy in polymer processing technologies}

Advances in Raman spectroscopy equipment allow more sophisticated application in polymer processing technologies. There are already available palm-sized devices like DeltaNU RapidID (Fig. 3). Compact size and no need of sample preparation allows direct application in filed or post analysis of measured data with specialized software (NuSpec). All measured datas are stored in internal memory.

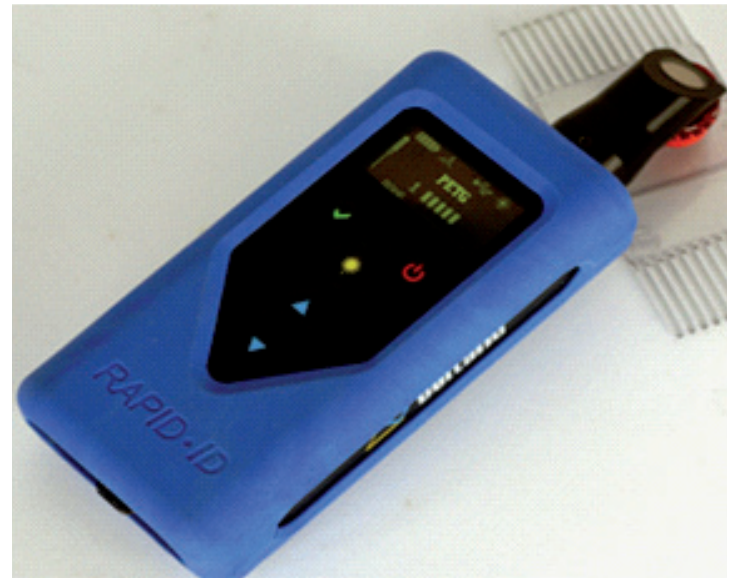

Fig. 3: DeltaNu RapidID, palm sized Raman spectrometer.

\section{Extrusion}

Because Raman spectroscopy uses excitation in the visible or NIR regions, the base unit containing the optical components and the computer used to control the instrument can be located remotely from the probe used to interface with the 
sample. Figure 4 shows Raman data acquired of polymer blends during extrusion. A 532-nm probe was coupled to the base unit using a 100-m optical fiber. For quantitation, the ratio of the components is easily determined from the area ratios of their spectral bands.

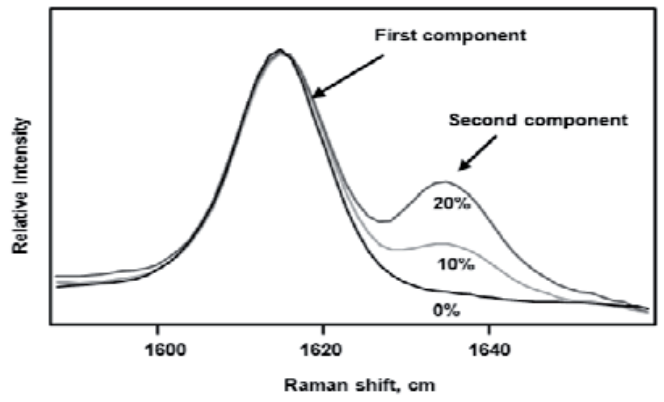

Fig. 4: On-line Raman spectroscopy of extruded polymer blends.

\section{Polyethylene Density}

One of the most important polymers used today is polyethylene (PE), with applications as diverse as milk jugs, insulation for wires, and gasoline tanks in automobiles. PE comes in two general forms: high- density polyethylene (HDPE) and lowdensity poly-ethylene (LDPE). HDPE is generally defined as polyethylene having a density in the range $0.955-0.970 \mathrm{~g} / \mathrm{cm}^{3}$, while LDPE has a density of $0.920-0.935 \mathrm{~g} / \mathrm{cm}^{3}$. HDPE has greater strength, less creep, and less gas permeability, while LDPE is more flexible and translucent.

Figure 5 contains spectra of polyethylene samples with densities of $0.96,0.910$, and $0.882 \mathrm{~g} / \mathrm{cm}^{3}$. Curve- fitting techniques can be used to create a calibration model to correlate the Raman spectrum of a PE sample to its density.

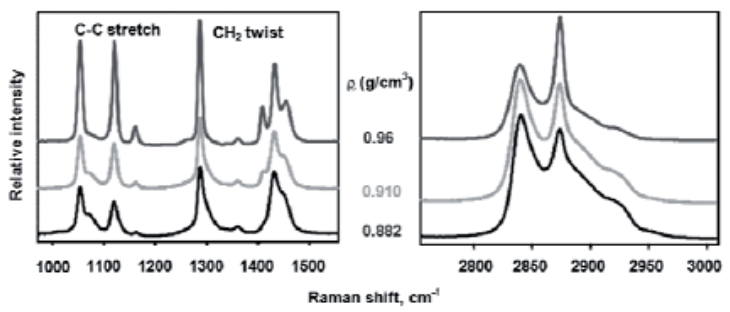

Fig. 5: Raman spectra comparing polyethylene sam- ples of various densities.

\section{Polybutadiene Microstructure}

Raman spectroscopy is especially useful for the characterization of polybutadienes because it can distinguish all of the fundamental structural units directly using the $\mathrm{v}(\mathrm{C}=\mathrm{C})$ bond stretching of 1,2-vinyl, 1,4-cis, and 1,4-trans units, which give rise to Raman bands at 1639, 1650, and $1664 \mathrm{~cm}^{-1}$, respectively. Figure 6 presents the application of Raman spectra by polymer micro-structure.

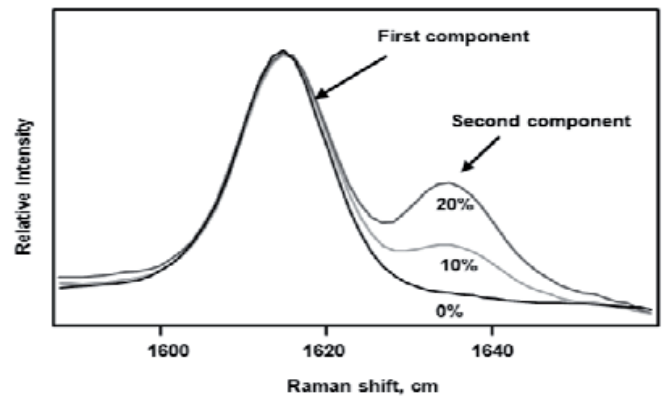

Fig. 6: Raman spectral region used to identify micro-structure of polybutadienes.

\section{On site monitoring of raw material}

Monitoring the composition of copolymers is very important because many grades are commercially available, with the properties-and pricedependent upon the distribution of the different monomers[4]. Figure 7 shows how copolymers of ethylene vinyl acetate can be distinguished according to the vinyl acetate fraction.Since 1970 we see increasing importance of modern metrology as means to control and improve industrial manufacturing and the quality ao all kinds of products and processes.[5]

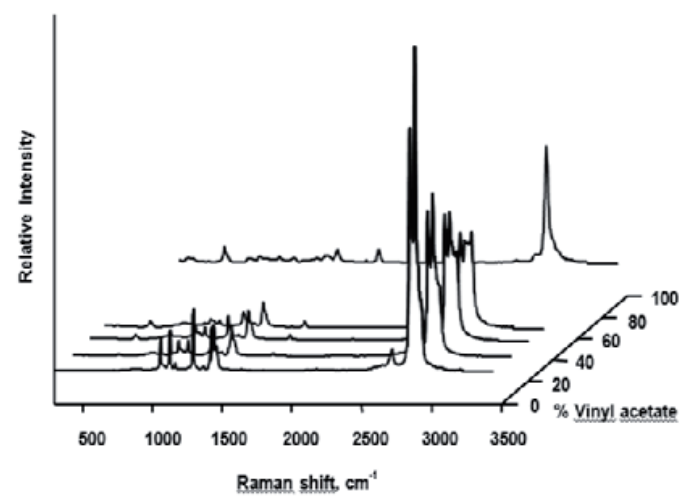

Fig. 7: Dependence of ethylene vinyl acetate co-polymers Raman spectra on vinyl acetate fraction. 


\section{Conclusion}

Raman spectroscopy is such a general technique that even reviewing briefly what can be done with it, even in the area of polymer processing technologies. The progress in development of Raman spectrometers equipment leads to simplified on-site application of Raman spectrometers. Measured diagrams present practical application of Raman spectra evaluation in polymer processing technologies. Although the results strongly depends on operator's knowledge of Raman scattering process to evaluate properly the gathered Raman spectra. Online applications like presented in figure 1, solve simplified problems because they are mostly operated with one type of polymer. Measured results shows also big potential of Raman spectrometry in polymer sorting in recycling industry.

\section{Acknowledge}

This contribution is the result of the project implementation: Center for research of control of technical, enviromental and human risk for permanent development of production and products in mechanical engineering (IMTS:26220120060) supported by the Research \& Development Operational Programme funded by the ERDF.

\section{References}

[1] Schrader, B.: Infrared and Raman Spectroscopy; Schrader, B. ed., VCH Publishers Inc.: New York, 1995; Chapter 4.

[2] Myers, A.B., Mathies, R.A.: Biological Applications of Raman Spectroscopy: Volume 2: Resonance Raman Spectra of Polyenes and Aromatics, Spiro, T.G. ed., John Wiley and Sons: New York, 1987; Chapter 1.

[3] Everall, N.: Raman Spectroscopy of Synthetic Polymers. In Analytical Applications of Raman Spectroscopy; Pelletier M.J., Ed. Blackwell: Oxford,1999; pp. 127-192.

[4] Красінський В.В., Шаповал Й.М., Целюх К.І.(студ.). Розроблення керованого процесу виготовлення феноло-формальдегідної композиції конкретного призначення при допомозі математичного планування композиційного складу // Тези доповідей Дев'ятої відкритої наукової конференції професорськовикладацького складу інституту прикладної математики та фундаментальних наук (17-18 листопада 2010 р.). Львів: Нац. Ун-т“Львівська політехніка", 2010. - С. 112.

[5] Durakbasa,M.N.,Osana,P.H.,: Inteligent design and metrology for higher quality,accuracy and improving production effciency, In: Acta Mechanica Slovaca, no.1/2011 vol.15, p.611 , ISSN 1335-2393
[6] Vranová,J., Rosina,J., Horak, J.,Hendrichova,M.,Kratka,K.: Isotope-selective infrared spectroscopy reveals pathological changes in the liver. In: Acta Mechanica Slovaca, no.2/2010 vol.14, p.60-65, ISSN 1335-2393

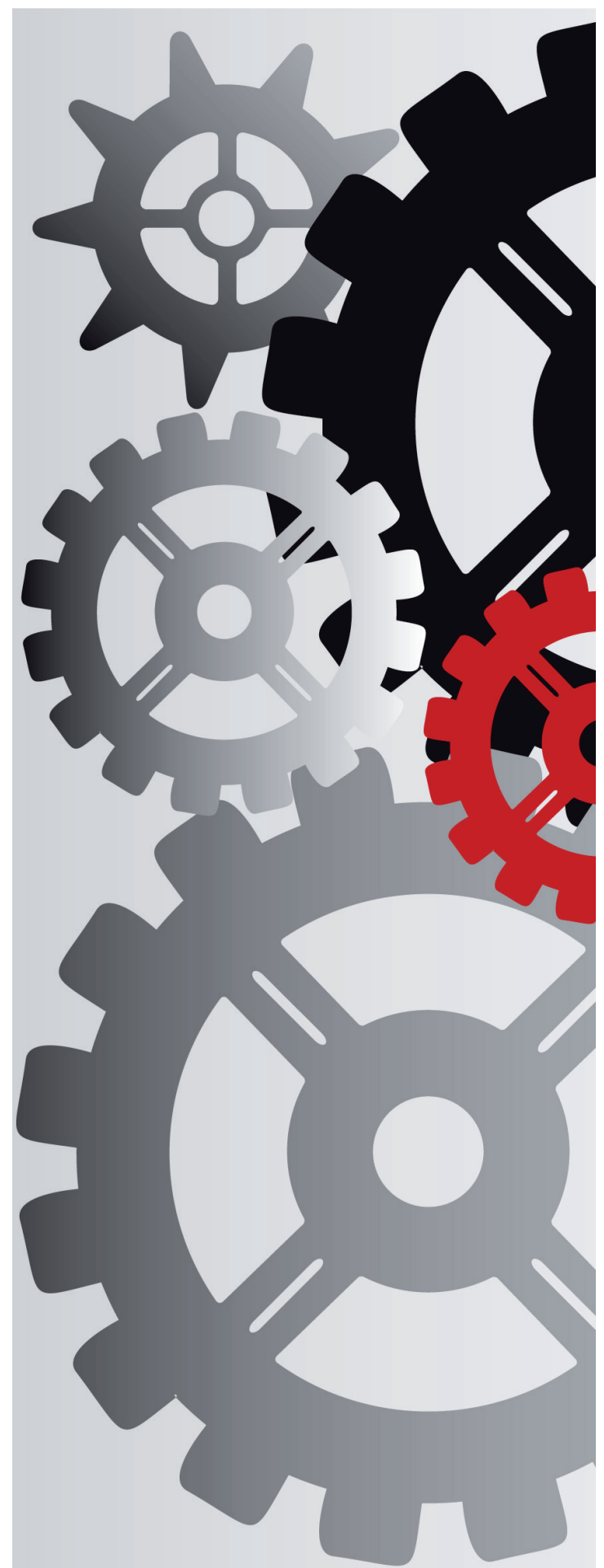

